\title{
La inclusión digital en la educación de Tarija, Bolivia
}

\author{
Sulma Farfán Sossa, Antonio Medina Rivilla \\ y María Luz Cacheiro González
}

RESUMEN

En este estudio se analiza la inclusión digital en la educación secundaria del Distrito Educativo de Tarija, Estado Plurinacional de Bolivia, en la gestión 2012-2013, conforme con los indicadores del Plan de Acción Regional eLAC. Esta investigación es exploratoria y de carácter descriptivo, con una muestra de 311 estudiantes, 108 profesores y 15 directores de establecimientos educacionales. Según los resultados, los adolescentes acceden a Internet buscando información y entretenimiento; la expansión de las tecnologías móviles entre ellos ofrece múltiples posibilidades educativas y la insuficiente formación de los profesores para la integración de las tecnologías de la información y las comunicaciones (TIC) en el proceso de enseñanza-aprendizaje es uno de los desafíos más importantes. Se ha determinado la existencia de las TIC en los establecimientos educacionales, pero no su uso. Los esfuerzos locales y nacionales están contribuyendo a reducir la brecha digital y promover la igualdad de oportunidades para los jóvenes.

PALABRAS CLAVE

CLASIFICACIÓN JEL

AUTORES
Educación, educación secundaria, escuelas públicas, brecha digital, innovaciones pedagógicas, internet, tecnología de la información, tecnología de las comunicaciones, programas de acción, igualdad de oportunidades, indicadores TIC, Bolivia (Estado Plurinacional de)

$\mathrm{I} 24, \mathrm{I} 25, \mathrm{I} 28$

Sulma Farfán Sossa es asesora en tecnología educativa de la Saint Louis University-Madrid, España. sfarfan@slu.edu

Antonio Medina Rivilla es catedrático de la Universidad Nacional de Educación a Distancia (UNED), España. amedina@edu.uned.es

María Luz Cacheiro González es catedrática de la Universidad Nacional de Educación a Distancia (UNED), España.mlcacheiro@edu.uned.es 


\section{I}

\section{Introducción}

Las tecnologías de la información y las comunicaciones (TIC) son hoy en día un bien necesario en la vida cotidiana. Sus ventajas las convierten en recursos estratégicos para el desarrollo de las nuevas economías basadas en el conocimiento.

Desde la Cumbre Mundial sobre la Sociedad de la Información (CMSI, 2003), el acceso, la disponibilidad y el uso de las TIC son temas fundamentales para el desarrollo social y económico de los pueblos. Esta nueva realidad ha demandado a los gobiernos la implementación de políticas y programas que garanticen su integración en la Sociedad de la Información y el Conocimiento. Una de las vías fundamentales para lograr esta integración es la educación, sobre la que recae la responsabilidad de formar a las nuevas generaciones en las competencias indispensables que conlleva la Sociedad de la Información.

Si bien las Tic son cada día más asequibles, existen diferencias importantes entre los países desarrollados y en desarrollo, lo que ha generado una gran disparidad en su acceso dando lugar a la "brecha digital".

Para superar las desigualdades generadas por las TIC, se están llevando a cabo en distintos países planes de inclusión digital que van más allá del simple equipamiento tecnológico (UNESCO, 2013a; Eurydice, 2011). En el caso del Estado Plurinacional de Bolivia, los primeros pasos en políticas de TIC se inician en el año 2002, pero es a partir del año 2005 cuando se establecen a nivel educativo, permitiendo llevar adelante diversos proyectos dirigidos a la reducción de la brecha digital.
En la presente investigación se recoge una variedad de propuestas de indicadores de las TIC en la educación que permiten determinar el avance de la inclusión digital, y se emplean los propuestos por el Plan de Acción Regional elaC de la Comisión Económica para América Latina y el Caribe (CEPAL, 2012a) en el análisis de los datos recogidos en el Distrito Educativo de Tarija. Asimismo, se han analizado otras investigaciones efectuadas en distintos departamentos del Estado Plurinacional de Bolivia y países vecinos.

El artículo se estructura de la siguiente manera. En la sección II se abordan los retos que plantea la llamada Sociedad de la Información. La sección III se refiere a la brecha y la inclusión digital, y asimismo a las grandes desigualdades en el acceso a las TIC. A su vez, en la sección IV se señala la necesidad de emplear indicadores que permitan conocer los niveles de inclusión digital en la educación. Por su parte, la sección V se aboca a la implementación de las TIC en la educación y en la sección VI se examina la inclusión digital en el Estado Plurinacional de Bolivia. En tanto que las secciones VII y VIII se refieren al contexto y la metodología con que se efectúa la investigación, en la sección IX se presentan las características de la muestra. En la secciones X y XI se realiza el análisis de resultados sobre la base de los indicadores, como también de acuerdo con otros estudios. Por último, en la sección XII se ofrecen las conclusiones de la investigación.

\section{II}

\section{Los retos de la Sociedad de la Información}

La Cumbre Mundial sobre la Sociedad de la Información de Ginebra (CMSI, 2003) y la de Túnez (CMSI, 2005) permitieron establecer una declaración explícita de la voluntad política de los países participantes tendiente a contribuir a "una Sociedad de la Información integradora, poner el potencial del conocimiento y las TIC al servicio del desarrollo, fomentar la utilización de la información y del conocimiento para la consecución de los objetivos de desarrollo acordados internacionalmente, incluidos los contenidos en la Declaración del Milenio (...)" (CMSI, 2003, pág. 2). En esta declaración se enfatiza la necesidad de incorporar a las TIC en la educación como un elemento estratégico para la inclusión digital de la sociedad. Esta tarea requiere inicialmente erradicar el analfabetismo básico y "definir políticas nacionales para garantizar la plena integración de las Tecnologías de Información y Comunicación (TIC) en todos los niveles educativos y de capacitación, incluyendo la elaboración 
de planes de estudio, la formación de los profesores, la gestión y administración de las instituciones, y el apoyo al concepto del aprendizaje a lo largo de toda la vida" (CMSI, 2003, pág. 6). Además, "velar porque los jóvenes dispongan de los conocimientos y aptitudes necesarios para utilizar las TIC, incluida la capacidad de analizar y tratar la información de manera creativa e innovadora, y de intercambiar su experiencia y participar plenamente en la Sociedad de la Información” (CMSI, 2003, pág. 6).

La Cumbre Mundial de la Sociedad de la Información y los Objetivos de Desarrollo del Milenio (ODM) se constituyeron en la base para impulsar el Plan de Acción Regional elAC por parte de la CEPAL. Este plan es una agenda política concertada con los países de la región, en que se concibe a las TIC como instrumento de desarrollo económico y de inclusión social.

Los planes elAC2007 y elAc2010 impulsaron los primeros pasos para la instalación de las condiciones tecnológicas en el ámbito educativo (eLAc2007 (2005) y eLAC2010 (2008)), pero es a partir del Plan elac2015 que se plantea que "la política de aprovechamiento de las tecnologías digitales en el contexto educativo debe concebirse como una política de Estado. Esta política deberá incluir, entre otras cosas, la formación avanzada de los profesores sobre temas tecnológicos, cognitivos y pedagógicos, la producción de contenidos digitales y de aplicaciones interactivas, metodologías innovadoras de enseñanza y aprendizaje y el aprovechamiento de recursos tecnológicos de avanzada, incluida la provisión de banda ancha y de otros dispositivos con potencial pedagógico transformador" (eLAC2015, 2010, pág. 13). En respuesta a este planteamiento, 31 de los 38 países de América Latina y el Caribe analizados en el estudio de la UNESCO (2013a) indican haber adoptado una definición formal (política nacional, plan nacional, institución reguladora y otros) vinculada a las iniciativas en que se utilizan las TIC en la educación.

En el Plan elac2015 (2010) se plantean cuatro metas relacionadas con la educación, dirigidas a promover la conectividad mediante banda ancha y el aumento de la densidad de ordenadores en los establecimientos educacionales, implementar políticas que impulsen la redes de investigación y educación, incrementar la formación del profesorado y de los equipos directivos, fomentar el desarrollo de aplicaciones interactivas multimedia con la participación y producción por parte de estudiantes y profesores y, por último, contar con el apoyo de la Red Latinoamericana de Portales Educativos (RELPE). Los avances registrados en América Latina y el Caribe con respecto a estas metas son muy diversos debido, principalmente, a la falta de continuidad de los proyectos, los consensos, el respaldo político, las políticas y los recursos, entre otros factores (Rovira y Stumpo, 2013).

\section{III}

\section{Brecha e inclusión digital}

Si bien los planes elac han impulsado un avance importante en la incorporación de las TIC en los países miembros, se observan grandes desigualdades en cuanto a su acceso, lo que se ha denominado "brecha digital".

El concepto de brecha digital aparece en 1999 en el informe Falling through the Net: Defining the Digital Divide del Departamento de Comercio de los Estados Unidos de América (NTIA, 1999). En este informe se define la brecha digital como la diferencia entre dos grupos: los que tienen y los que no tienen acceso a una computadora, a Internet y al servicio telefónico y sus contenidos, al tiempo que se muestra la repercusión de las tecnologías en la vida de las personas.

Por su parte, la Organización de Cooperación y de Desarrollo Económico (OCDE, 2001, pág. 5) define la brecha digital como la diferencia que existe entre individuos, hogares, empresas y zonas geográficas de diferentes niveles socioeconómicos en relación con sus oportunidades para acceder a las TIC, así como al uso de Internet en una amplia variedad de oportunidades.

Las Naciones Unidas (2001) indican que la existencia de la brecha digital es una consecuencia de la disparidad de los ingresos de los países, cuya reducción es un objetivo mundial. Se indica, también, que las Tic son un factor de desarrollo humano y que todos los países deben contar con políticas nacionales que impulsen el uso, difusión y aprovechamiento en diferentes ámbitos y colectivos.

Ballestero (2002) identifica cuatro elementos relacionados con la brecha digital:

- Disponibilidad de los equipos que permitan conectarse a Internet. 
- $\quad$ Posibilidad de acceder a Internet.

- Conocimiento que permita acceder y navegar en la red.

- Capacidad para convertir la informacion de la red en conocimiento para el benificio del usuario.

En diversos estudios (Ballestero, 2002; Agustín y Clavero, 2010; Rovira y Stumpo, 2013) se manifiesta que las tecnologías traen grandes beneficios para los que las tienen y saben usarlas, generando la exclusión de aquellos que no las tienen o no las saben usar. Para superar esta situación se planteó un concepto que va más allá del equipamiento, denominado inclusión digital y se concibe "como una forma de inserción social imprescindible para el crecimiento comunitario, que surge como superación de la dimensión netamente cuantitativa y tecnológica del concepto de brecha digital" (Agustín y Clavero, 2010, pág. 149).

La inclusión digital se ha definido como el "conjunto de políticas públicas relacionadas con la construcción, administración, expansión, creación y desarrollo de contenidos en las redes digitales públicas, alámbricas e inalámbricas, en cada país, región o comunidad. Incluye las garantías de privacidad y seguridad ejercidas de manera equitativa para todos. Abarca el adiestramiento y el incentivo para desarrollar herramientas nuevas" (Robinson, 2005, pág. 127).

Por otra parte, en el "Informe sobre la implantación y el uso de las TIC en los centros docentes de educación primaria y secundaria" se destaca el papel central que juegan las TIC en el desarrollo de la economía y la sociedad, y se indica que todos aquellos pueblos que no trabajen en su inclusión digital quedarán al margen del desarrollo mundial (Instituto de Evaluación y Asesoramiento Educativo/Neturity/Fundación German Sánchez Ruipérez, 2007).

A partir de la CMSI se han establecido diversos indicadores que permiten conocer el grado de inclusión digital de la sociedad, comparar los diferentes esfuerzos realizados en los países y establecer acciones futuras para mejorar sus resultados.

\section{IV}

\section{Indicadores de la Inclusión Digital en la Educación}

Las Naciones Unidas han sugerido el replanteamiento de los sistemas educativos, considerando las ventajas que traen consigo las TIC y su repercusión en el desarrollo humano (Naciones Unidas, 2001). Esta tarea requiere inicialmente determinar los niveles de inclusión digital en la educación, para lo cual es necesario emplear indicadores que se han establecido con este fin a nivel mundial o regional.

A partir de la CMSI, en 2005 se publicó un conjunto de indicadores TIC, cuya elaboración estuvo a cargo de los miembros de la Asociación para la Medición de las TIC para el Desarrollo (2010), quienes han revisado y ampliado los indicadores en todos los ámbitos. A continuación se citan los referidos a la educación:

1. Proporción de escuelas que usan un receptor de radio con fines educativos.

2. Proporción de escuelas que usan un televisor con fines educativos.

3. Proporción de escuelas con servicio telefónico.
4. Número de alumnos por computadora.

5. Proporción de escuelas con acceso a Internet, por tipo de acceso.

6. Proporción de alumnos que tienen acceso a Internet en la escuela.

7. Proporción de alumnos matriculados en el nivel terciario en áreas relacionadas con las TIC.

8. Proporción de personal docente de escuelas primarias y secundarias capacitado en las TIC.

9. Proporción de escuelas que tienen electricidad.

Según el estudio realizado por la Organización de las Naciones Unidas para la Educación, la Ciencia y la Cultura (UNESCO, 2013a), las metas de la CMSI relacionadas directamente con la educación son las metas 2 y 7 y sus indicadores:

Meta 2. Utilizar las TIC para conectar a escuelas primarias y secundarias.

1. Proporción de escuelas que cuentan con una radio para uso pedagógico. 
2. Proporción de escuelas que cuentan con un televisor para uso pedagógico.

3. Razón de alumnos por computadora.

4. Proporción de escuelas con acceso a Internet, por tipo de acceso.

Meta 7. Adaptar los planes de estudio de las escuelas primarias y secundarias al cumplimiento de los objetivos de la Sociedad de la Información, teniendo en cuenta las circunstancias de cada país.

1. Proporción de docentes calificados en las TIC en las escuelas.

2. Proporción de docentes capacitados para enseñar materias mediante el uso de las TIC.

3. Proporción de establecimientos educativos con enseñanza asistida por computadora.

4. Proporción de establecimientos educativos con enseñanza asistida por Internet.

En el caso del Plan elaC2015, se han planteado seis indicadores relacionados con la educación (CEPAL, 2012a).

1. Relación alumnos/computadora por nivel educacional.

2. Proporción de niños y jóvenes que asisten a la escuela que han usado Internet en un establecimiento educativo.

3. Proporción de niños y jóvenes que asisten a la escuela que han usado Internet en actividades de educación o aprendizaje, por nivel educacional.

4. Porcentaje de maestros de primaria y secundaria capacitados para enseñar una o varias asignaturas escolares utilizando recursos de las TIC por nivel educacional.

5. Porcentaje de grados que utilizan enseñanza asistida por las TIC (niveles 1-3), por asignatura: matemáticas, ciencias, conocimientos básicos computacionales (informática), idiomas, arte.

6. Proporción de contenidos educativos públicos digitalizados.

Por otra parte, el Banco Interamericano de Desarrollo (BID) publicó un conjunto de indicadores para el desarrollo de un proyecto de las TIC en educación (Severin, 2010). En la propuesta se establecen dos tipos de indicadores: de insumos y de salida, que incluyen aspectos por medir tales como infraestructura, contenidos, gestión, políticas, y otros.

La Organización de Estados Iberoamericanos para la Educación, la Ciencia y la Cultura (OEI) planteó cuatro indicadores que permiten evaluar el grado de inclusión digital en la educación: disponibilidad de las TIC, organización de la escuela para el uso de estas, formación de los educadores en su uso y presencia de las TIC en las prácticas pedagógicas (OEI, 2011).

Las propuestas recopiladas en esta sección muestran coincidencias en varios de sus indicadores, sin embargo, dado el contexto de la investigación se analizan los indicadores del Plan de Acción Regional elAC.

\section{V}

\section{Implementación de las TIC en la educación}

Los países desarrollados fueron pioneros en la implementación de las TIC en la educación. En el caso de la Unión Europea, se evidencian importantes avances y logros cuyos aspectos más sobresalientes se citan a continuación (Eurydice, 2011):

- Todos los países cuentan con políticas nacionales sobre las TIC que abarcan todo el proceso de aprendizaje.

- El número promedio de estudiantes por ordenador es de 2 a 4.

- Se ofrecen ayudas públicas para adquisición de las TIC con fines educativos.

- Todos los países evalúan sus estrategias nacionales referidas a las Tic y la educación.
- La mayoría de los países europeos utilizan las TiC en todas las áreas del currículo.

- El acceso a Internet por banda ancha es casi generalizado en los países de la Unión Europea.

- Los establecimientos educativos cuentan con páginas web, sistemas de seguimiento académico, entre otros.

Por otra parte, en el informe Eurydice (2011) se identifican los siguientes retos:

- La formación en las Tic es uno de los aspectos más débiles y requiere especial atención para lograr la inclusión digital de los profesores.

- $\quad$ El uso de Internet está orientado al juego más que a la educación. 
El informe ha constatado que los estudiantes acceden a Internet desde sus casas más que desde el establecimiento educativo, hecho que podría deberse principalmente al bajo coste y la alta velocidad que se ofrece por el servicio de Internet en la Unión Europea (CEPAL, 2012b).

Cabe destacar que los porcentajes de cada uno de los aspectos indicados son diferentes en cada país miembro de la Unión Europea.

En el caso de América Latina y el Caribe, la integración de las TIC en la educación primaria y secundaria presenta un importante avance, gracias a la adopción de políticas y programas nacionales. En el estudio realizado por el Instituto de Estadística de la UNESCO en países de América Latina y el Caribe (UNESCO, 2013a) se exponen los siguientes resultados:

a) Proporción de escuelas que usan un receptor de radio con fines educativos

Catorce países del Caribe reportan el uso de radio con fines educativos, pero con porcentajes diferentes (por ejemplo, las Bahamas: $100 \%$ de establecimientos educativos de primaria y secundaria y Dominica: $38 \%$ de primaria y $80 \%$ de secundaria).

\section{b) Proporción de escuelas que usan un televisor con fines educativos \\ Veintidós países reportan el uso de la enseñanza} asistida por televisión. Los países del Caribe son los que más reportan el uso de esta tecnología. De los países latinoamericanos, el Brasil y México son los que más han trabajado en esta línea.

Los países indicados en el informe han realizado grandes inversiones en la implementación de estaciones de radio, televisión o ambas con fines educativos.

\section{c) Número de alumnos por computadora}

Existen grandes diferencias entre los países latinoamericanos y los caribeños. Por ejemplo, en el Uruguay existe una computadora por alumno, a diferencia de otros países como la República Dominicana, donde hay 122 alumnos por computadora. Sin tomar en cuenta estos casos extremos, la razón de alumnos por ordenador es de 27 en primaria y 17 en secundaria.

De los 28 países que abarca el estudio, el 100\% manifiestan contar con laboratorios de informática tanto en primaria como en secundaria. En el estudio se indica que los laboratorios de informática contribuyen a reducir la brecha de acceso a las TIC. d) Proporción de escuelas con acceso a Internet, por tipo de acceso

En 15 países caribeños, el $100 \%$ de sus establecimientos educativos secundarios están conectados a Internet. Estos porcentajes varían si se trata de conexión de banda ancha.

Los países latinoamericanos reportan importantes porcentajes de conexión a Internet, aunque no todos llegan al 100\%. La diferencia de porcentajes es mayor cuando se trata de establecimientos educacionales con acceso a Internet mediante banda ancha.

En el caso del Uruguay, el acceso por banda ancha es del $95 \%$ en establecimientos de primaria y del $100 \%$ en secundaria.

Los datos muestran que el nivel secundario es privilegiado con respecto al primario en el acceso a Internet y banda ancha.

e) Proporción de personal docente de escuelas primarias y secundarias capacitado en las TIC

Según el informe, solo 14 países reportan datos en cuanto a formación del profesorado. Se observa que menos del 10\% de los docentes de primaria y secundaria están calificados para el uso de las TIC en la educación. Existen grandes diferencias entre países como es el caso de la Argentina, que reporta un 3\% de docentes formados en las TIC, y Aruba, con el $100 \%$.

f) Proporción de escuelas que tienen electricidad

Según el estudio, todas las escuelas de primaria y secundaria del Caribe, exceptuando a las de la República Dominicana, cuentan con servicio eléctrico.

El Uruguay cuenta con el $96 \%$ de escuelas de primaria y el $100 \%$ de secundaria con energía eléctrica.

Existen diferencias importantes en los países sudamericanos y centroamericanos. Menos del 80\% de las escuelas primarias del Ecuador, Guyana, Panamá y la República Bolivariana de Venezuela cuentan con servicio eléctrico.

En el estudio se resalta que el servicio eléctrico favorece a la educación secundaria.

Los indicadores presentados, tanto europeos como latinoamericanos, muestran importantes diferencias en el acceso y equipamiento de las TIC en la educación; pero en ambos estudios se coincide en la necesidad de formar a los docentes en el uso didáctico de las tecnologías para la incorporación exitosa de estas en el proceso de enseñanza-aprendizaje. 


\section{VI}

\section{La inclusión digital en el Estado Plurinacional de Bolivia}

Como todos los países miembros de la CEPAL, el Estado Plurinacional de Bolivia viene dando importantes pasos para lograr la inclusión digital y el impulso a la Sociedad de la Información. Un claro ejemplo de esto es la creación en 2002 de la Agencia para el Desarrollo de la Sociedad de Información en Bolivia (ADSIB), cuyo objetivo es la reducción de la brecha digital.

A principios del año 2004, se crea la Estrategia Boliviana de Tecnologías de la Información y la Comunicación para el Desarrollo (ETIC). A partir de 2007, se establece el Plan Nacional de Inclusión Digital que procura desarrollar la sociedad del conocimiento en el Estado Plurinacional de Bolivia. Respecto del período 2012-2014, se establece la Agenda Digital Boliviana para la implementación de una estrategia de desarrollo de las TIC (Rovira y Stumpo, 2013).

En el ámbito de la educación se avanzó significativamente en el año 2005, con el establecimiento de la Política Nacional de Nuevas Tecnologías de la Información y Comunicación para la Educación. Un año más tarde se estableció el Programa Nacional de TICs, cuyo objetivo es proporcionar acceso y uso adecuado de las TIC a todo el Sistema Educativo Nacional y a la comunidad en general, a través de la instalación de Telecentros Comunitarios de Educación y la difusión del Portal Educativo, con contenidos adecuados y contextualizados al país, fomentando de este modo una amplia participación ciudadana (Ministerio de Educación, 2006).

En paralelo al establecimiento de políticas sobre las TIC, se ha trabajado en la democratización del acceso a la electricidad como indicador imprescindible para la inclusión digital y el desarrollo de la sociedad de la información. Según el informe del Ministerio de Hidrocarburos y Energía (2010), el acceso a la electricidad es del 90,4\% en el área urbana y del 50,8\% en el área rural, con una proyección del $100 \%$ de acceso en el área urbana para el año 2015 y el año 2025 en el área rural. La ampliación de la cobertura eléctrica, sumada a las tecnologías móviles, está permitiendo que cada vez más usuarios bolivianos tengan acceso a las TIC y sus servicios (véase el cuadro 1).

\begin{tabular}{lr}
$\begin{array}{ll}\text { CUADRO } 1 \\
\text { Indicadores de las TIC en el Estado } \\
\text { Plurinacional de Bolivia, 2012-2013 }\end{array}$ \\
\hline Servicio & Unidades \\
\hline Conexiones a Internet & 2000000 \\
Usuarios de Facebook & 2002000 \\
Teléfonos móviles & 9306800 \\
Teléfonos inteligentes & 527185 \\
Hogares con telefonía fija o celular & 2013623 \\
Hogares con aparatos de radio & 2101942 \\
Hogares con televisor & 1891270 \\
Computadoras en los hogares & 657050
\end{tabular}

Fuente: elaboración propia sobre la base de datos del Instituto Nacional de Estadística (INE), Estado Plurinacional de Bolivia. Características de la población y vivienda. Censo Nacional de Población y Vivienda 2012 [en línea] http://www.ine.gob.bo:8081/ censo2012/PDF/resultadosCPV2012.pdf; y M. Campos, "Santa Cruz, líder en usuarios de internet y redes sociales", El Día, 2013 [en línea] http://eldia.com.bo/index.php?cat=357\&pla=3\&id_ articulo $=120867$

Nota: población en el Estado Plurinacional de Bolivia: 10.027.254. Número de hogares; 2.812.715.

Según los datos presentados por el Observatorio Regional de Banda Ancha de la CEPAL, la penetración de Internet en el Estado Plurinacional de Bolivia llega al 30\% de la población. El costo de conexión a la banda ancha fija representa el $31,42 \%$ del ingreso per cápita y a la banda ancha móvil un 11,28\%. Según el mismo informe, la velocidad para subir o bajar información de Internet es la más baja de América del Sur (CEPAL, 2012b). En respuesta a esta situación, el Gobierno boliviano ha puesto en marcha el satélite Túpac Katari, cuyo objetivo es mejorar el acceso y reducir los costes referidos a Internet, telefonía y televisión (ABI, 2013).

Por otra parte, en la Ley de Educación "Avelino Siñani-Elizario Pérez" de 2010 se plantea entre los objetivos: "Desarrollar una formación científica, técnica, tecnológica y productiva (...) en complementariedad con los avances de la ciencia y la tecnología universal en todo el Sistema Educativo", así como: "Promover la investigación científica, técnica, tecnológica y pedagógica en todo el Sistema Educativo Plurinacional (...)" (Ministerio de Educación, 2010, págs. 9 y 12). En este marco se llevan adelante diversos proyectos 
y programas, tales como: "Una Computadora por Docente", "Telecentros educativos comunitarios", el "Portal Educativo Nacional", "Una Computadora por Estudiante", desarrollo de material educativo para radio y televisión y otros (véase el cuadro 2), encaminados a incorporar a las TIC en todos los niveles de la educación (Crespo y Medinaceli, 2013).

CUADRO 2

\section{Inclusión digital en la educación boliviana,} 2011-2013

\begin{tabular}{lr}
\hline Indicador & Unidades \\
\hline Computadoras portátiles distribuidas a profesores & 132693 \\
Telecentros educativos comunitarios instalados & 340 \\
Computadoras en establecimientos educacionales & 10000 \\
Docentes capacitados por programas estatales & 15000 \\
Razón de estudiante por computadora & $55^{\text {a }}$ \\
\hline
\end{tabular}

Fuente: elaboración propia sobre la base de Ministerio de Educación, "Una computadora por docente", 2011 [en línea] http://computadora. educabolivia.bo/; y Organización de las Naciones Unidas para la Educación, la Ciencia y la Cultura (UNESCO), "Uso de las TIC en la Educacion en América Latina y el Caribe. Análisis regional de la integración de las TIC en la educación y de la aptitud digital (e-readiness)", Quebec, 2013 [en línea] http://www.uis.unesco.org/ Communication/Documents/ict-regional-survey-lac-2012-sp.pdf.

a Organización de las Naciones Unidas para la Educación, la Ciencia y la Cultura (UNESCO, 2013a).
El proyecto "Una Computadora por Docente" es una de las acciones más importantes para la inclusión digital de los docentes bolivianos. Su objetivo es brindar a los profesores acceso a las TIC para que estos desarrollen procesos educativos mediante las herramientas y los contenidos instalados en las computadoras (Ministerio de Educación, 2011). En este proyecto se incluye la formación técnica para el uso de los equipos, y pedagógica para el trabajo en la clase.

Además de las iniciativas públicas, existen acciones de la cooperación internacional y de organizaciones no gubernamentales (ONG) nacionales y extranjeras dirigidas a la inclusión digital en la educación (Red TICBolivia, Ayni Bolivia, Educatic y otras), que ofrecen oportunidades de formación en las TIC, desarrollo de contenidos, difusión de información y equipamiento, entre otros.

Cada día las TIC están más presentes en la educación boliviana, por lo que es de vital importancia contar con publicaciones o informes de resultados que permitan cuantificar los avances y evaluar la inclusión digital en la educación.

En el caso del departamento de Tarija, no se cuenta con estudios previos sobre esta temática, aunque las inversiones en las TIC han sido continuas tanto desde el gobierno nacional como del regional.

\section{VII}

\section{Contexto de la investigación}

El departamento de Tarija, ubicado al sur del Estado Plurinacional de Bolivia, está constituido por seis provincias (Cercado, Aniceto Arce, Burdet O'Connor, Gran Chaco, Eustaquio Méndez y José María Avilés). Tiene una población de 482.196 habitantes, de los cuales aproximadamente el $40 \%$ vive en la provincia Cercado cuya capital es la ciudad de Tarija (INE, 2012). Toda la provincia Cercado constituye el Distrito Educativo de Tarija y es el lugar donde se ha desarrollado la presente investigación.

En el año 2013, el Distrito Educativo de Tarija concentró el $42 \%$ de la población estudiantil entre 5 y 19 años (53.829 estudiantes) de todo el departamento, según datos proporcionados por la Dirección Departamental de Educación, que es la institución estatal encargada de la educación del departamento.

Según la Dirección Distrital de Educación, que es la institución pública encargada de la educación del Distrito de Tarija, en el año 2013 se contaba con 2.700 docentes y 20.043 estudiantes de nivel secundario público. De los 197 establecimientos educativos, 64 impartían educación secundaria pública y se localizaban en el área urbana y rural de la provincia Cercado. El $40 \%$ de la población estudiantil del Distrito cursa el nivel secundario y pronto se convertirá en la fuerza laboral de la región, razón por la cual el análisis del estudio se centra en este nivel educativo. 


\section{VIII}

\section{Metodología de la investigación}

El presente estudio tiene por objetivo analizar la inclusión digital en la educación secundaria pública boliviana del Distrito Educativo de Tarija, de acuerdo con los indicadores de las TIC establecidos por el Plan de Acción Regional eLAC. Al estudio se suman tres indicadores referidos a las condiciones básicas de energía eléctrica, radio y televisión como recursos educativos.

Se trata de una investigación exploratoria de carácter descriptivo, basada en encuestas cerradas dirigidas a profesores, estudiantes y directores de establecimientos educativos.

Las encuestas aplicadas se elaboraron sobre la base de otras desarrolladas en el ámbito de la educación y las TIC, como: Profesión y Docencia (Gallego, 2009), Informe de las Tecnologías de la Informacion y de la Comunicación en la Educación (Instituto de Evaluación y Asesoramiento Educativo/Neturity/Fundación Germán Sánchez Ruipérez, 2007), y Proyecto Universidad y Sociedad del Conocimiento: ¿Es el e-learning la única respuesta? (Gewerc, 2007), esta última aplicada en dos universidades bolivianas. Las encuestas han sido validadas por profesionales que trabajan en el ámbito de las TIC y la educación, en el Estado Plurinacional de Bolivia y España.

Los datos se han recogido durante las gestiones correspondientes a 2012 y 2013, aplicando encuestas en formato impreso debido a las limitaciones de conectividad. El proceso de recopilación de datos contó con la colaboración de la Dirección Distrital de Educación de Tarija, la Dirección de Educación del Departamento y la Dirección de Educación del Gobierno Autónomo Municipal.

Los establecimientos educativos seleccionados corresponden al nivel secundario. Cada uno de estos recibió un número y para su selección se usó el método aleatorio. En la aplicación de las encuestas dentro de cada establecimiento educacional se empleó también el muestreo aleatorio.

\section{IX}

\section{Características de la muestra}

La muestra es de 311 estudiantes cuyas edades fluctúan entre 13 y 18 años, de los cuales el 52\% son mujeres y el $48 \%$ son varones. El $67 \%$ de los estudiantes pertenecen a la zona urbana y el $33 \%$ al área rural.

De los 108 profesores, son varones el $51 \%$ y mujeres el $49 \%$. La presencia femenina ha sido mayoritaria en dos rangos de edad: 25 a 30 años (21\%) y 51 a 55 años (19\%), mientras que el rango con mayor participación de hombres es el de 31 a 35 años (24\%). En la encuesta se han recogido datos de una gran diversidad de profesores, desde aquellos que se inician en la labor docente hasta los que tienen una larga experiencia profesional (véase el gráfico 1).

La información proporcionada por los 15 directores de los establecimientos educativos encuestados en el estudio ha permitido determinar que el $60 \%$ de los establecimientos que participaron en la investigación cuentan con los niveles de infantil, primaria y secundaria, mientras que en el $40 \%$ solo se imparte el nivel secundario. Según los datos, 10 establecimientos educativos se ubican en el centro y periferia de la zona urbana y 5 en el área rural del Distrito Educativo de Tarija. 
GRÁFICO

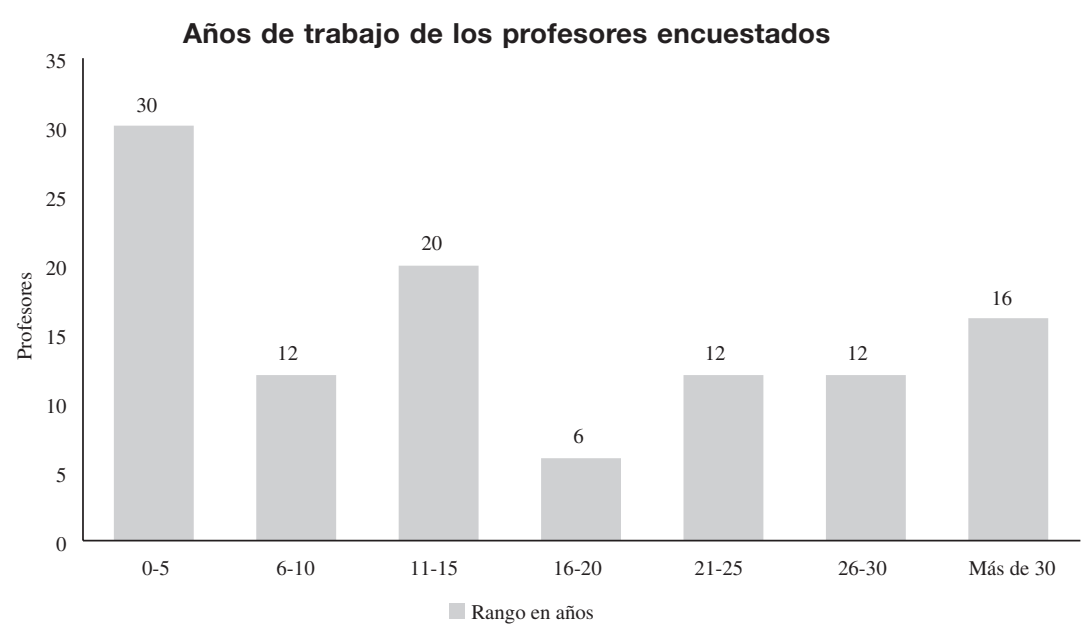

Fuente: elaboración propia sobre la base de datos de la encuesta aplicada a profesores para este estudio.

\section{X}

\section{Análisis de resultados sobre la base de los indicadores}

El análisis se inicia con tres indicadores que permiten conocer las condiciones de las TIC en los establecimientos educativos (Asociación para la Medición de las Tic para el Desarrollo, 2010). A partir del cuarto indicador (relación estudiantes/computadora por nivel educacional), se especifican los referidos al Plan de Acción Regional eLAC.

\section{Un indicador de partida: el acceso a la electricidad}

Según el informe del Ministerio de Hidrocarburos y Energía (2010), la cobertura eléctrica en la provincia Cercado del departamento de Tarija supera el 80\%, lo que permite que 194 (98\%) de los establecimientos educativos cuenten con energía eléctrica, según datos facilitados por la Dirección de Educación del Gobierno Autónomo Municipal de Tarija. Cabe destacar que el $100 \%$ de los establecimientos que imparten nivel secundario cuentan con acceso al servicio eléctrico. Este hecho coincide con los datos del estudio de la UNESCO (2013a), que indican que la educación secundaria tiene prioridad respecto del nivel primario en este aspecto.

\section{Proporción de escuelas que usan receptor de radio con fines educativos}

Según la información proporcionada por la Dirección Distrital de Educación de Tarija, el 100\% de los establecimientos educacionales cuentan con al menos una radio con fines educativos. Por otra parte, los datos recogidos indican que el $20 \%$ de los establecimientos encuestados cuentan en las aulas con una radio con fines educativos.

Los establecimientos de secundaria disponen de receptores de radio; sin embargo, en el proceso de investigación se ha evidenciado que en el Estado Plurinacional de Bolivia las emisoras de radio educativas se enfocan exclusivamente en la formación adultos (IRFA, ACLO, FIDES y otras).

\section{Proporción de escuelas que usan un televisor con fines educativos}

El 52\% de los establecimientos cuentan con al menos un televisor con fines educativos según la Dirección Distrital de Educación de Tarija. Según los datos de la 
encuesta, el $40 \%$ de los establecimientos educacionales cuentan con televisores en las aulas.

En esta línea, el Gobierno boliviano ha establecido entre sus estrategias el desarrollo de material para radio y televisión (Crespo y Medinaceli, 2013) e impulsa el proyecto de televisión digital, que tiene una señal dirigida a la educación y la cultura (El Deber, 2012). En este nuevo escenario, se abren inéditas posibilidades para el uso de la televisión en el proceso de enseñanza-aprendizaje en el Estado Plurinacional de Bolivia.

\section{Relación estudiantes/computadora por nivel educacional}

Con el fin de ofrecer igualdad de oportunidades en el acceso a la computación, el Gobierno boliviano ha planteado la distribución de una computadora por estudiante, acción que se ha iniciado en el Distrito Educativo de Tarija en el mes de septiembre de 2014 y está dirigida al nivel secundario (Ministerio de Educación, 2014). Este proyecto permitirá reducir la razón obtenida en este estudio de 18 estudiantes por computadora.

El 93\% de los establecimientos educativos encuestados cuenta con al menos una sala de computación, con un promedio de 17 computadoras. Sin embargo, los recortes producidos al rescindir los contratos de los responsables de las TIC de los laboratorios de informática están provocando la subutilización de las infraestructuras instaladas, como se evidenció en el proceso de investigación a través de las autoridades educativas.
Comparando estos resultados con los datos registrados en el Estado Plurinacional de Bolivia en el año 2009, con una razón de 55 estudiantes por computadora (UNESCO, 2013a), el avance hacia la inclusión digital es significativo.

\section{Proporción de niños y jóvenes que asisten a la escuela y que han usado Internet en un establecimiento educativo}

Según la encuesta, el 28\% de los estudiantes acceden a Internet desde el establecimiento educativo. Asimismo, el estudio ha evidenciado que el espacio más utilizado por los estudiantes para acceder a Internet es el café-Internet (46\%), como se muestra en el gráfico 2.

Los resultados muestran también que, de los 74 estudiantes que tiene computadora e Internet en el hogar, el $28 \%$ utiliza el café-Internet.

Por otra parte, en el estudio se ha determinado que el $53 \%$ de las salas de computación de los establecimientos educativos cuentan con el $100 \%$ de sus equipos conectados a Internet, el $27 \%$ disponen de algunos equipos conectados y el $20 \%$ restante indica no contar con conexión a Internet.

Asimismo, en los 15 establecimientos educativos analizados se ha constatado la existencia de las TIC en las aulas en diversos porcentajes; por ejemplo: el $47 \%$ cuenta con computadora en las aulas, un $27 \%$ tiene conexión a Internet, un $20 \%$ dispone de proyectores multimedia y un $13 \%$ con altavoces.

GRÁFICO 2

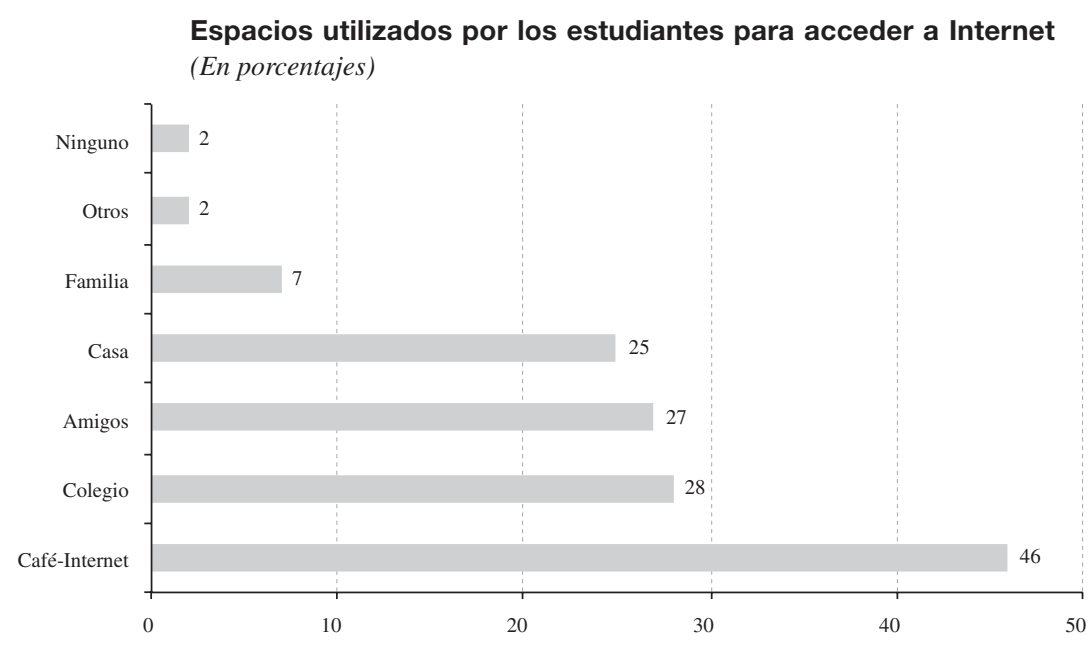

Fuente: elaboración propia sobre la base de los datos de la encuesta aplicada a estudiantes para el presente estudio. 
El $47 \%$ de los establecimientos educacionales no poseen equipamiento tecnológico en las aulas. Esta es una de las razones por las que no se usan las TIC en el proceso enseñanza-aprendizaje, tal como lo indica la directora del establecimiento educativo Aniceto Arce, la profesora Sonia Lema Ruiz al diario El Nacional (Velásquez, 2013).

Las limitaciones del establecimiento educativo no son un impedimento para que los estudiantes accedan a Internet, ya que — como se muestra en el estudioel $93 \%$ de los encuestados indican tener teléfono celular y de estos, el $46 \%$ se ha conectado a Internet mediante este dispositivo. Este dato coincide con el informe de la Autoridad de Regulación y Fiscalización de Telecomunicaciones y Transportes del Estado Plurinacional de Bolivia, en el que se indica que la población boliviana accede cada día más a Internet por medio de dispositivos móviles (ATT, 2012). Este dato debe ser considerado como muy relevante en la educación, dado que el avance de las tecnologías móviles y su fácil manejo ofrecen múltiples posibilidades para el trabajo en el aula (UNESCO, 2013b).

Según los resultados de la encuesta, el 44\% de los estudiantes acceden a Internet al menos dos veces a la semana y permanecen conectados una hora como promedio.

El equipamiento existente en los establecimientos educativos es un aspecto favorable, aunque existen desafíos importantes por superar como el número de computadoras disponibles para los estudiantes, el acceso a Internet en todos los equipos y llevar las TIC al aula como un recurso en el proceso de enseñanza-aprendizaje.

\section{Proporción de niños y jóvenes que asisten a la escuela y que han usado Internet en actividades de educación o aprendizaje, por nivel educacional}

El $80 \%$ de los estudiantes manifiestan tener al menos una clase a la semana con empleo de las TIC, del cual un $43 \%$ corresponde a establecimientos educativos del área rural, lo que muestra el interés de los profesores por introducir las TIC en la educación.

El 87\% de los estudiantes manifiestan usar Internet con fines educativos, específicamente en la búsqueda de información. Este porcentaje señala la importancia que tiene Internet como fuente de información para los adolescentes (véase el gráfico 3).

Los resultados permiten evidenciar que las actividades de diversión en el ciberespacio están muy presentes en la vida de los adolescentes.

Por otra parte, la investigación ha mostrado que los estudiantes han desarrollado competencias en el manejo de las TIC, especialmente en los paquetes ofimáticos (PowerPoint, Word y otros) y navegadores de Internet (véase el gráfico 4).

En este nuevo contexto, el reto del profesor es orientar estas competencias tanto en la adquisición de conocimientos puntuales como para el aprendizaje a lo largo de la vida.

GRÁFICO 3

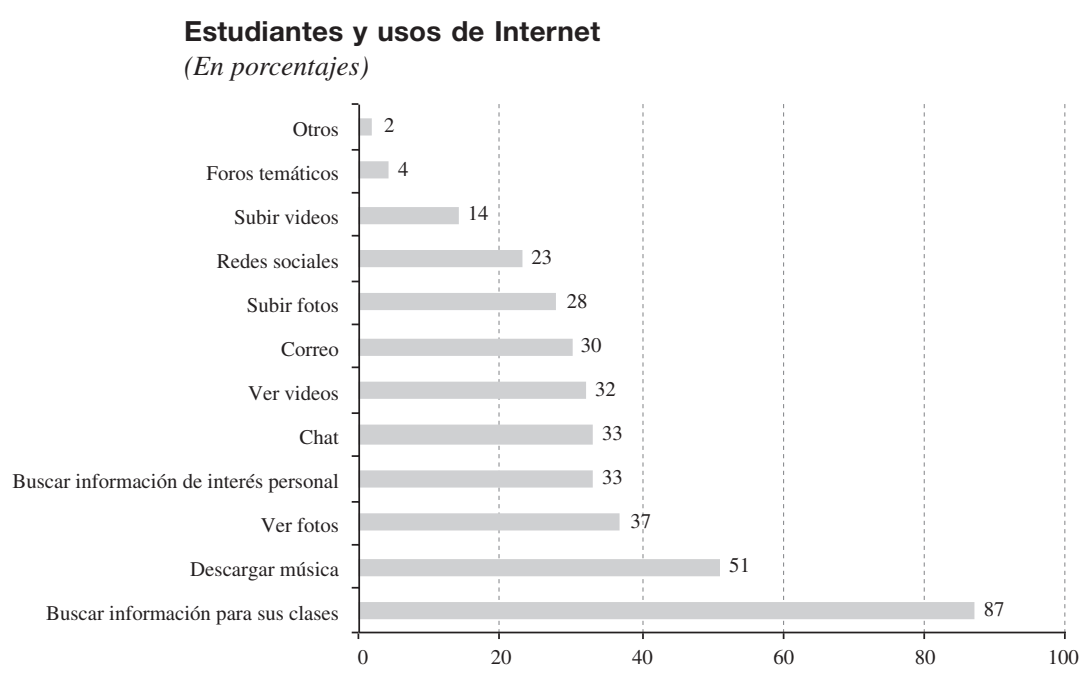

Fuente: elaboración propia sobre la base de los datos de la encuesta aplicada a estudiantes para el presente estudio. 
GRÁFICO 4

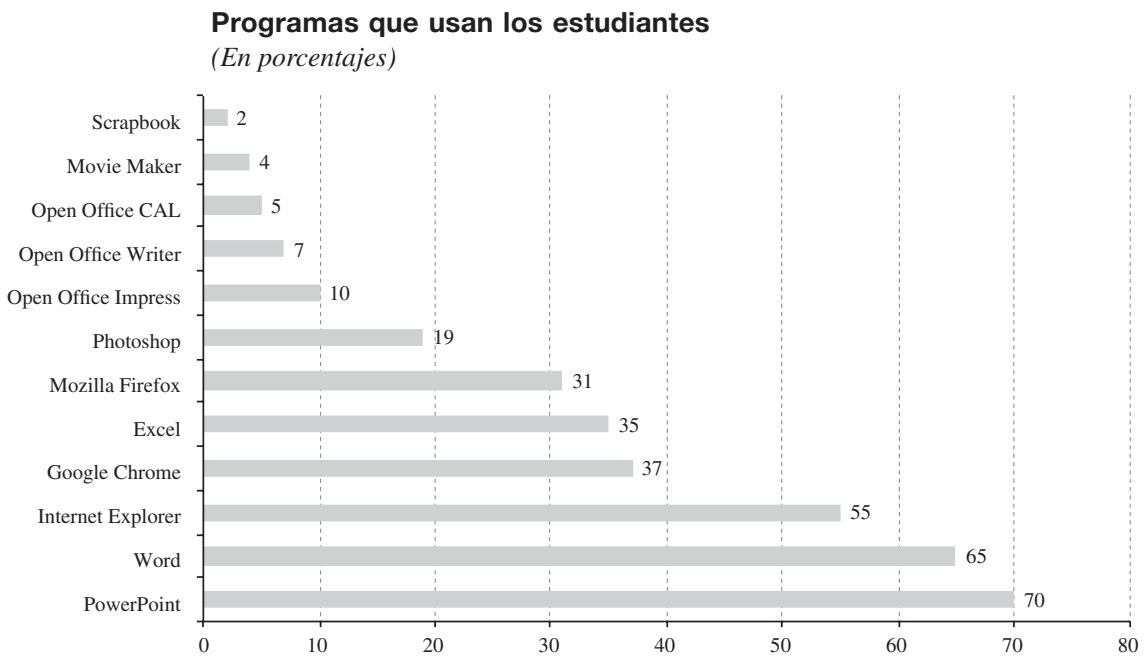

Fuente: elaboración propia sobre la base de los datos de la encuesta aplicada a estudiantes para el presente estudio.

Según el cruce de datos, el $50 \%$ de los estudiantes que saben usar PowerPoint y Word y el 47\% de los que utilizan Internet Explorer y Google Chrome no cuentan con una computadora en casa.

El 65\% de los estudiantes encuestados indican tener un perfil en Facebook, un 15\% en Google Plus y un 14\% en Twitter. El 23\% de los adolescentes manifiestan ser usuarios en más de una red social. Este dato señala al educador un nuevo espacio que puede utilizarse con el fin de promover aprendizajes a través del trabajo colaborativo y social.

El porcentaje de estudiantes que acceden a los servicios de Internet es elevado, sin embargo, se ha identificado que el $37 \%$ de mujeres y el $23 \%$ de varones no tienen una cuenta de correo electrónico. El $41 \%$ de las mujeres y el $45 \%$ de hombres revisan el correo electrónico dos o más veces a la semana. Estos datos evidencian que los adolescentes acceden frecuentemente a Internet, por lo tanto, la tarea del educador es orientar el acceso a las TIC hacia un fin educativo.

El 53\% de los estudiantes indican haber publicado contenidos en Internet, de los cuales un $23 \%$ ha subido algún video a YouTube, un $17 \%$ ha creado alguna animación de fotos en la web, un $11 \%$ ha creado alguna página web y un $9 \%$ ha subido fotos a Flikr. Estos resultados muestran que los jóvenes están pasando de ser consumidores de información a ser creadores en la red, de ahí la importancia de los programas de prevención y control de los peligros en el ciberespacio.
Los estudiantes están buscando diversas formas de acceder a las tecnologías y en especial a Internet como un medio de expresión y "construcción de su identidad" (Morduchowicz, 2012, pág. 68). Además, "en el mundo de los adolescentes, está bien no entender las matemáticas, pero no es nada 'guay' el no saber usar un ordenador o el no tener un teléfono móvil” (TACCLE, 2009, pág. 55). En esta nueva realidad, la tarea del profesor como orientador es fundamental para encaminar el entusiasmo de los adolescentes por las TIC hacia el aprendizaje.

\section{Porcentaje de maestros de primaria y secundaria capacitados para enseñar una o varias asignaturas escolares por nivel educacional utilizando recursos de las TIC}

Los profesores, tanto hombres como mujeres, manifiestan haber adquirido sus conocimientos sobre las TIC mediante cursos particulares o de pago y por medio de estudio personal (autodidactas). Se observa también que el porcentaje de profesores varones formados, es mayor que el de mujeres (véase el gráfico 5).

Los resultados dejan ver la necesidad de seguir trabajando en programas de formación, a fin de reducir estas diferencias de género y garantizar la inclusión digital de todo el sector docente.

Los profesores encuestados prefieren la formación presencial (44\%) y mixta (virtual-presencial, $43 \%$ ), en comparación con la formación completamente virtual (12\%). 
GRÁFICO 5

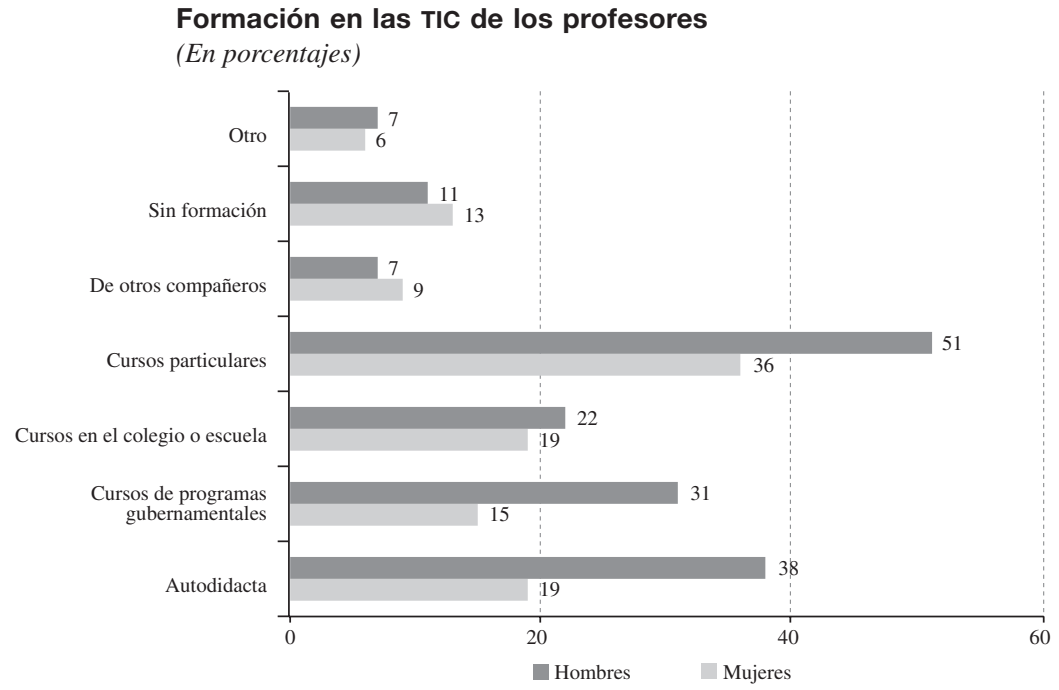

Fuente: elaboración propia sobre la base de los datos de la encuesta aplicada a profesores para el presente estudio. TIC: tecnologías de la información y las comunicaciones.

Una de las razones por las que la educación virtual no es una opción para los profesores obedece al limitado acceso a Internet. Según la encuesta, el 53\% de las profesoras y el $56 \%$ de los profesores no tienen Internet en casa.

El 58\% de los profesores manifiestan la necesidad de ser formados en la integración de las TIC en el currículo y práctica educativa, así como en la formación técnica para el uso de la computadora y programas informáticos (véase el gráfico 6).

Los resultados evidencian la necesidad de un plan de formación integral pedagógico y tecnológico, que permita el desarrollo de la creatividad y de las competencias en las TIC del profesorado.

GRÁFICO 6

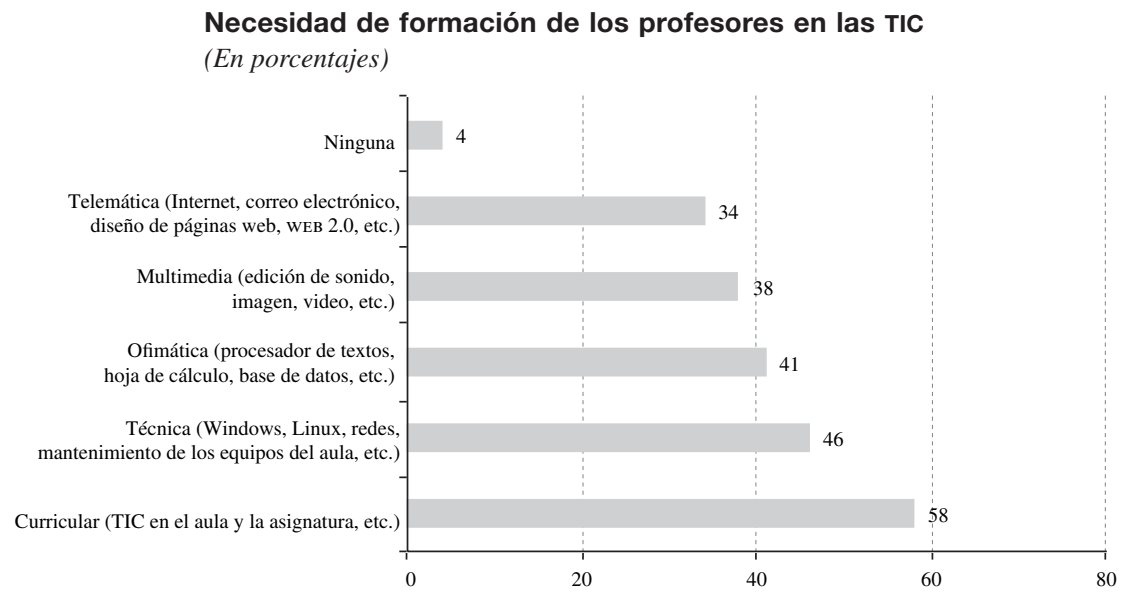

Fuente: elaboración propia sobre la base de los datos de la encuesta aplicada a profesores para el presente estudio. TIC: tecnologías de la información y las comunicaciones.

Ofimática: conjunto de programas informáticos que facilitan el trabajo de oficina. 
Los profesores manifiestan tener conocimientos en los paquetes ofimáticos (44\% en hojas de cálculo, $53 \%$ en procesador de texto y $28 \%$ en presentaciones multimedia), manejo del hardware (51\%), funciones básicas del sistema operativo (69\%). Sin embargo, desconocen el software para la construcción de recursos multimedia como editores de sonido $(67 \%)$, imágenes $(61 \%)$ y video $(68 \%)$. Esta situación constituye una limitante a la hora de construir contenidos interactivos y contextualizados que respondan a las nuevas necesidades educativas. En este sentido, el Ministerio de Educación, dentro del proyecto "Una Computadora por Docente", plantea la formación para la construcción de recursos educativos como una fase dentro de su plan de capacitación (Ministerio de Educación, 2011).

Con respecto a los recursos de Internet, un alto porcentaje de profesores manifiestan usar el correo electrónico $(80 \%)$, el chat $(63 \%)$, los navegadores de Internet $(60 \%)$ y los buscadores de información (74\%); sin embargo, no conocen y les gustaría usar recursos como: blogs (87\%), wikis (92\%), foros (79\%), videos en la web $(72 \%)$, plataformas educativas $(85 \%)$, redes sociales $(68 \%)$ y videoconferencias $(85 \%)$, entre otros. Estos resultados muestran que los profesores desconocen las diversas posibilidades educativas que ofrece el ciberespacio.

El $63 \%$ de los profesores declara usar Internet para preparar sus clases, mostrando así la importancia de los contenidos web como fuente de información del profesorado.

Los resultados manifiestan que los profesores elaboran diversos recursos para sus clases, basados especialmente en paquetes ofimáticos; no obstante existe un $22 \%$ que declara no usar recursos informáticos de elaboración propia (véase el gráfico 7).
Según datos obtenidos de la Dirección Distrital de Educación de Tarija, la formación actual del profesorado está dirigida al manejo de la computadora; sin embargo, el desafío es la capacitación en el uso de las TIC para mejorar el proceso de enseñanza-aprendizaje, lo que incluye la creación de recursos digitales.

\section{Proporción de contenidos educativos públicos digitalizados}

Según información facilitada por la Dirección de Educación del Gobierno Autónomo Municipal de Tarija, el Distrito Educativo no cuenta con un portal de recursos regionales, pero existe un proyecto para su próximo desarrollo.

A nivel nacional, el Ministerio de Educación ha creado el portal Educabolivia, como un proyecto dentro del Programa Nacional de Nuevas Tecnologías de la Información y la Comunicación para la Educación, dirigido a los actores del proceso educativo: padres, docentes y estudiantes. El portal "brinda elementos que complementan la educación y el desarrollo comunitario ofreciendo información, recursos, servicios y experiencias educativas y de calidad que respondan a las necesidades e intereses de la comunidad educativa" (Educabolivia, 2013).

El portal está estructurado en cuatro secciones: Docentes, Comunidad, Estudiantes y Recursos. Las tres primeras secciones permiten acceder a información actualizada para cada población objetivo, mientras que la última está destinada a facilitar el acceso a recursos educativos (véase el cuadro 3 ).

Desde su creación en 2007, el portal Educabolivia representa un avance importante, especialmente en la introducción de recursos que respondan a la ley educativa y al contexto.

GRÁFICO 7

Recursos elaborados por los profesores

(En porcentajes)

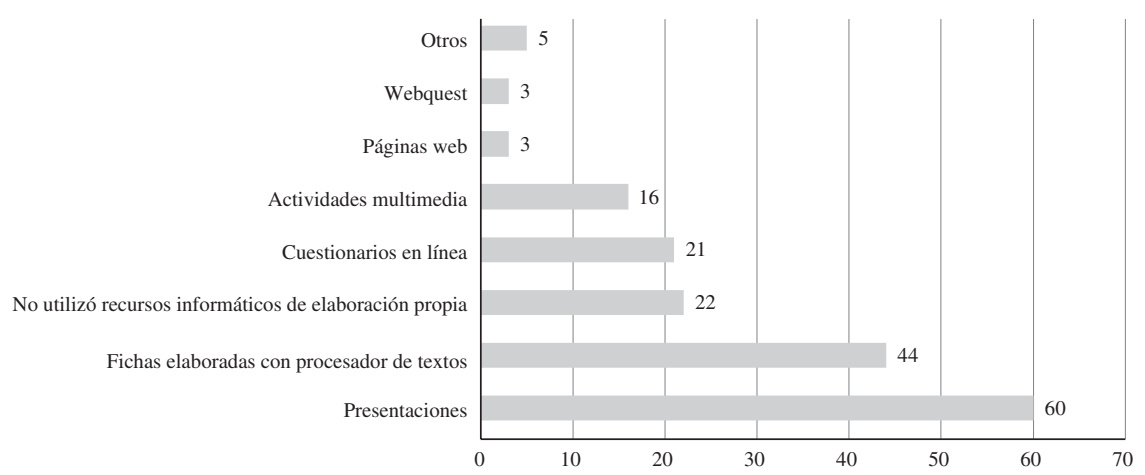

Fuente: elaboración propia sobre la base de los datos de la encuesta aplicada a profesores para el presente estudio. 
CUADRO 3

Recursos del portal Educabolivia

\begin{tabular}{|c|c|c|}
\hline Sección del portal & Contenido & Número y tipo de recursos \\
\hline Sitios educativos & Vincula desde el portal a sitios educativos externos. & 1061 vínculos a sitios web \\
\hline Planificación & $\begin{array}{l}\text { Ofrece al educador pautas para la planificación didáctica de un contenido } \\
\text { educativo. }\end{array}$ & 329 propuestas didácticas \\
\hline Textos & $\begin{array}{l}\text { Permite la descarga y el acceso a un resumen sobre el contenido de los } \\
\text { textos que se listan. }\end{array}$ & 347 títulos \\
\hline Juegos & $\begin{array}{l}\text { Existen una serie de juegos educativos creados por organizaciones no } \\
\text { gubernamentales con sede en el Estado Plurinacional de Bolivia. Los juegos } \\
\text { están clasificados por área de conocimiento. }\end{array}$ & $\begin{array}{l}15 \text { juegos educativos para nivel } \\
\text { infantil, } 32 \text { para primaria y } 23 \\
\text { para secundaria }\end{array}$ \\
\hline Biblioteca & Lista de una serie de bibliotecas virtuales de acceso libre. & 11 vínculos \\
\hline Sonidos & $\begin{array}{l}\text { Espacio que facilita el acceso a audios libres que se pueden descargar desde } \\
\text { el portal. }\end{array}$ & 11 audios \\
\hline Presentaciones & $\begin{array}{l}\text { Espacio que contiene presentaciones en PowerPoint de diferentes temas, } \\
\text { según nivel educativo. }\end{array}$ & 15 presentaciones \\
\hline Software & $\begin{array}{l}\text { Permite la descarga de diferentes programas de computación educativos. } \\
\text { Cuenta con una pequeña descripción y se especifica el nivel al que va dirigido. }\end{array}$ & \\
\hline Imágenes & $\begin{array}{l}\text { Cuenta con un banco de imágenes que van acompañadas de una breve } \\
\text { descripción. }\end{array}$ & 495 imágenes \\
\hline Videos & Esta sección dispone de videos/animaciones educativos. & 24 videos/animaciones \\
\hline
\end{tabular}

Fuente: elaboración propia sobre la base de información de Educaboliva, 2013 [en línea] http://www.educabolivia.bo/.

\section{XI}

\section{Análisis de resultados de acuerdo con otros estudios}

De forma paralela a la presente investigación, Terrazas e Ibarra (2013) realizaron otro estudio sobre las TIC y educación en el departamento de La Paz-Estado Plurinacional de Bolivia, con una muestra de 100 estudiantes de secundaria. Este estudio ha permito analizar aspectos comunes (véase el cuadro 4).

Según la investigación de Terrazas e Ibarra (2013), los estudiantes de La Paz usan las TIC para hacer relaciones sociales y muy poco para la aplicación en la búsqueda de información en la web.

Con respecto a los profesores, los investigadores indican que las computadoras donadas dentro del marco del proyecto "Una Computadora por Docente" están subutilizadas debido a la brecha digital generacional entre estudiantes y profesores, la falta de capacitación para su uso y el temor de los maestros a probar con las nuevas tecnologías, coincidiendo con lo expuesto en esta investigación.

La tendencia de los resultados del estudio de Terrazas e Ibarra (2013) coincide de forma general en varios aspectos con la presente investigación.
Por otra parte, el estudio realizado por el Centro de Estudios de la Realidad Económica y Social (CERES), la organización Ciudadanía y el periódico Los Tiempos en el departamento de Cochabamba (CEREs/Ciudadanía/ Los Tiempos, 2013) ha determinado que la población, en general, emplea Internet para: estudiar o aprender (38\%), trabajar (36\%), participar en redes sociales (23\%) y contactar con amigos y familia (21\%).

Este estudio evidencia que los jóvenes entre 18 y 25 años utilizan Internet para estudiar y aprender. Este dato permite conocer la tendencia sobre el uso de Internet, en coincidencia con el presente estudio que ha identificado que los adolecentes emplean Internet en la búsqueda de información para sus clases.

A nivel latinoamericano se han realizado estudios similares, como el elaborado en el Perú por Balarin (2013), en el que se señala que los establecimientos educativos tienen bajos porcentajes de acceso a Internet (un $17,4 \%$ en primaria y el $36,7 \%$ en secundaria). La razón estudiante por computadora es de 5 en primaria y 9 en secundaria debido, principalmente, al Programa 
Contraste de estudios realizados en La Paz y Tarija, 2012-2013

\begin{tabular}{|c|c|}
\hline Estudiantes de La Paz & Estudiantes de Tarija \\
\hline $\begin{array}{l}\text { Los estudiantes acceden a Internet de forma mayoritaria } \\
\text { por el café-Internet. }\end{array}$ & $\begin{array}{l}\text { El } 46 \% \text { de los estudiantes acceden a Internet mediante un } \\
\text { café-Internet. }\end{array}$ \\
\hline $\begin{array}{l}\text { Los estudiantes manifiestan acceder a Internet desde sus } \\
\text { teléfonos celulares. }\end{array}$ & $\begin{array}{l}\text { El } 46 \% \text { de los estudiantes encuestados en Tarija manifiestan } \\
\text { haber accedido a Internet por su teléfono. }\end{array}$ \\
\hline $\begin{array}{l}\text { El porcentaje de estudiantes que acceden a Internet desde su } \\
\text { casa es del } 1 \% \text {. }\end{array}$ & $\begin{array}{l}\text { El } 25 \% \text { de los estudiantes indican acceder a Internet desde } \\
\text { su casa. }\end{array}$ \\
\hline $\begin{array}{l}\text { La mayoría no cuenta con una computadora ni con Internet } \\
\text { en casa. }\end{array}$ & $\begin{array}{l}\text { El } 51 \% \text { de los estudiantes no cuentan con una computadora } \\
\text { en casa. }\end{array}$ \\
\hline $\begin{array}{l}\text { Los adolescentes tampoco tienen acceso a un telecentro o a las } \\
\text { salas de computación del establecimiento educativo, porque no } \\
\text { existen infraestructuras adecuadas. }\end{array}$ & $\begin{array}{l}\text { Un } 28 \% \text { de los estudiantes usan las salas de computación } \\
\text { del establecimiento educativo para acceder a una computadora } \\
\text { e Internet. }\end{array}$ \\
\hline Los estudiantes indican tener práctica en paquetes ofimáticos. & $\begin{array}{l}\text { Los estudiantes usan diversos paquetes ofimáticos PowerPoint } \\
(70 \%) \text {, Word }(65 \%) \text {, Excel }(35 \%) \text {. }\end{array}$ \\
\hline $\begin{array}{l}\text { El 54\% de los encuestados advierten que el uso de Internet } \\
\text { está enfocado a mejorar la búsqueda de información e } \\
\text { investigación. }\end{array}$ & $\begin{array}{l}\text { El } 87 \% \text { de los estudiantes manifiestan usar Internet para la } \\
\text { búsqueda de información para sus clases. }\end{array}$ \\
\hline $\begin{array}{l}\text { Un } 16 \% \text { no identifica un uso específico de las TIC en las } \\
\text { actividades educativas. }\end{array}$ & $\begin{array}{l}\text { Un } 30 \% \text { de los estudiantes manifiestan tener al menos una } \\
\text { clase a la semana con las TIC. }\end{array}$ \\
\hline
\end{tabular}

Fuente: elaboración propia sobre la base de L. Terrazas y J. Ibarra, Estrategia de integración de las TIC en el sistema de educación en los municipios de La Paz y El Alto, 2013 [en línea] http://www.pieb.com.bo/sipieb_notas.php?idn=8169.

One Laptop Per Child (oLPC) bajo el modelo "un niño, un ordenador", así como a la instalación de centros de recursos tecnológicos en los establecimientos educativos. Además de la entrega de computadoras, se han distribuido 80.000 paquetes de robótica en primaria y secundaria y 12.860 televisores. Desde el año 2008, la educación peruana cuenta con una televisión y un portal educativos con diversos recursos digitales. Por otra parte, el 67,9\% de los profesores de primaria y el $70,7 \%$ de secundaria han recibido capacitación en el uso de la computadora.

Según este estudio, los adolescentes peruanos han desarrollado competencias en el manejo de las TIC (ofimática, buscadores de información y computadora), lo que favorece su inclusión digital. Sin embargo, el acceso a Internet en los establecimientos educativos y la formación de los profesores en el uso didáctico de las TIC son los principales retos (Balarin, 2013).

En otro estudio realizado en Buenos Aires (Lago, 2012) se aprecia un importante avance en la inclusión digital en la educación, debido principalmente a la existencia de proyectos locales y nacionales, como el proyecto Conectar Igualdad creado el año 2010, a través del cual se ha distribuido una computadora a cada estudiante y profesor del sistema de educación público. Esta acción ha ido acompañada de una gran inversión en la instalación de las tecnologías necesarias para la conexión a Internet de los establecimientos educativos.

En el estudio de Lago (2012) se ha identificado que la formación del profesorado, la conexión a Internet, el ancho de banda y las dificultades técnicas, son algunos de los desafíos para la incorporación de las TIC en el aula. También se ha evidenciado que el uso de las computadoras por parte de los estudiantes se orienta a la diversión (juegos, videos, música y otros). Según el estudio, el impacto de la computadora en el hogar es muy significativo, ya que acerca a la familia del estudiante al mundo digital, constituyéndose en un importante avance para la Sociedad de la Información.

Los estudios internacionales citados coinciden con la presente investigación al señalar que los retos en formación del profesorado, equipamiento y conectividad de banda ancha son algunas prioridades para la inclusión digital en la educación. 


\section{XII}

\section{Conclusiones}

La investigación ha llegado a las siguientes conclusiones:

- Los indicadores utilizados, así como los estudios locales e internacionales analizados, han permitido poner de manifiesto que la educación boliviana y en especial la tarijeña avanzan hacia la inclusión digital.

- En el estudio se ha determinado la existencia, pero no el uso de las TIC en el proceso de enseñanzaaprendizaje del nivel secundario.

- Todos los establecimientos educativos de nivel secundario cuentan con acceso a servicio eléctrico, factor fundamental para la inclusión digital.

- La existencia de televisores en los establecimientos educativos es un aspecto favorable, aunque no garantiza la conectividad a la televisión digital mediante la cual se emite el canal educativo.

- En el caso de la radio, se han desarrollado experiencias en la formación de adultos; sin embargo, en la educación secundaria no se han observado proyectos específicos, aunque un elevado porcentaje de establecimientos educativos cuenta con este dispositivo.

- La ejecución del proyecto "Una Computadora por Estudiante" incide directamente en la razón estudiante/computadora, favoreciendo la reducción de la brecha digital del nivel secundario en el Distrito Educativo de Tarija.

- El reducido ancho de banda en la conexión a Internet del país (CEPAL, 2012b) y la razón, aún elevada, de estudiantes por computadora en los establecimientos educativos deriva en que los alumnos busquen caminos alternativos para acceder a la red como el café-Internet.

- La rápida expansión de las tecnologías móviles en el Estado Plurinacional de Bolivia están permitiendo que los estudiantes accedan a estas de forma masiva, creando un nuevo espacio con múltiples posibilidades para la educación (UNESCO, 2013b).

- Los estudiantes han adquirido competencias en el manejo de la computadora y diferentes programas informáticos, coincidiendo con los estudios citados en la investigación.

- $\quad$ El uso de Internet por parte de los estudiantes está orientado a la búsqueda de información y al entretenimiento.

- Los estudiantes se conectan a Internet al menos dos veces por semana.

- La formación del profesorado se debe en gran medida al entusiasmo y esfuerzo personal, sin embargo, se han identificado diferencias de género con respecto al tipo de formación recibida.

- La incorporación de las TIC en la malla curricular educativa es una de las necesidades más importantes identificada por el profesorado, reafirmando que el desafío de la incorporación de las TIC en la educación no es necesariamente el equipamiento, sino la formación de los profesores en su uso didáctico, pedagógico y creativo para lograr un impacto en la mejora del proceso formativo (Crespo y Medinaceli, 2013).

- Los establecimientos educativos están contribuyendo a la inclusión digital, y en la medida en que amplíen sus horarios de atención y mejoren las condiciones tecnológicas y de conectividad, aportarán a la igualdad de oportunidades de los jóvenes en la Sociedad de la Información y el Conocimiento.

- Las condiciones tecnológicas existentes y los proyectos gubernamentales están impulsando la inclusión digital del Distrito Educativo de Tarija, sin embargo, este es un proceso que requiere, en el tiempo, importantes inversiones para el mantenimiento, renovación y ampliación de la infraestructura tecnológica, así como la formación continua de los actores del proceso educativo.

- El estudio realizado representa un relevante aporte cuantitativo y descriptivo, que puede ser complementado con preguntas abiertas para recoger la percepción de los participantes, lo que permitirá un análisis cuantitativocualitativo más amplio respecto de las TIC en el ámbito educativo. 


\section{Bibliografía}

ABI (Agencia Boliviana de Información) (2013) [en línea] http:// www3 abi.bo/\#

ACLO (s/f) [en línea] http://aclo.org.bo/bolivia/.

Agustín, M.C. y M. Clavero (2010), "Indicadores sociales de inclusión digital: Brecha y participación ciudadana", Derecho, gobernanza y tecnologías de la información en la sociedad del conocimiento, F. Galindo-Ayuda y A. Rover (eds.), Zaragoza, Prensas Universitarias de Zaragoza [en línea] http://eprints. rclis.org/14264/.

Asociación para la Medición de las TIC para el Desarrollo (2010), "Indicadores clave sobre TIC" [en línea] http://www.itu.int/ dms_pub/itu-d/opb/ind/D-IND-ICT_CORE-2010-PDF-S.pdf.

ATT (2012) [en línea] http://att.gob.bo/index.php/component/content/ category/124-sisatt.

Ayni Bolivia [en línea] http://www.redayni.org/.

Balarin, M. (2013), "Programa Tic y educación básica. Las políticas TIC en los sistemas educativos de América Latina. Caso Perú" [en línea] http://www.unicef.org/argentina/spanish/Peru_ok.pdf.

Ballestero, F. (2002), La brecha digital. El riesgo de la exclusión en la sociedad de la información, Madrid, Fundación Retevisión.

Campos, M. (2013), "Santa Cruz, líder en usuarios de internet y redes sociales", El Día [en línea] http://eldia.com.bo/index. php?cat=357\&pla=3\&id_articulo=120867.

CEPAL (Comisión Económica para América Latina y el Caribe) (2012a), "Lista de indicadores para el eLAC2015", Documento de Proyecto, Santiago de Chile [en línea] http://www.iadb.org/ intal/intalcdi/PE/2012/10486.pdf.

(2012b), Estado de la banda ancha en América Latina y el Caribe, 2012. Informe del Observatorio Regional de Banda Ancha (ORBA), Santiago de Chile [en línea] http://www. eclac.org/publicaciones/xml/9/48449/EstadobandaAnchaen AMLC.pdf.

CEREs (Centro de Estudios de la Realidad Económica y Social)/ Ciudadanía/Los Tiempos (2013), "Cochabambinos usan Internet principalmente para estudiar o aprender y luego para trabajar" [en línea] http://www.ceresbolivia.org/ archivos/745

CMSI (Cumbre Mundial sobre la Sociedad de la Información) (2005), "Compromiso de Túnez" [en línea] http://www.itu.int/wsis/ docs2/tunis/off/7-es.html.

(2003), "Declaración de Principios" [en línea] http://www. itu.int/wsis/docs/geneva/official/dop-es.html.

Crespo, A. y K.I. Medinaceli (2013), "Políticas en tecnologías de la información y comunicación en el nuevo contexto social y educativo en Bolivia", Revista OIDLES, vol. 7, № 14 [en línea] http://www.eumed.net/rev/oidles/14/educacion-bolivia.html.

Educabolivia (2013) [en línea] http://www.educabolivia.bo/.

Educatic (s/f) [en línea] http://www.educatic.org.bo/.

elac2015 (2010), Plan de Acción sobre la Sociedad de la Información y del Conocimiento de América Latina y el Caribe (eLAC 2015), Lima [en línea] http://www.eclac.org/ socinfo/noticias/documentosdetrabajo/0/41770/2010-819eLAC-Plan_de_Accion.pdf.

elac2010 (2008), Plan de Acción Regional sobre la Sociedad de la Información en América Latina y el Caribe (eLAC2010), El Salvador [en línea] http://www.eclac.org/cgi-bin/getprod. asp?xml=/elac2015/noticias/paginas/9/44099/P44099. xml\&xsl=/elac2015/tp1/p18f.xs1\&base=/elac2015/tp1/topbottom.xsl.

elac2007 (2005), Plan de Acción sobre la Sociedad de la Información de América Latina y el Caribe (eLAC2007), Río de Janeiro [en línea] http://www.eclac.org/cgi-bin/getprod.asp?xml=/elac2015/ noticias/paginas/7/44097/P44097.xml\&xsl=/elac2015/tpl/p18f. xsl\&base=/elac2015/tpl/top-bottom.xsl.

El Deber (2012), "Presidente lanza el canal estatal", 10 de mayo [en línea] http://www.eldeber.com.bo/nota.php?id=120510222153.
Eurydice (2011), Cifras clave sobre el uso de las TIC para el aprendizaje y la innovación en los centros escolares de Europa 2011 [en línea] http://eacea.ec.europa.eu/education/eurydice/ documents/key_data_series/129ES.pdf.

Gallego, D. (2009), "Profesión y docencia: El nuevo perfil de la profesión docente. Informe 2007”, IV Congreso Internacional de Educared "Educar en comunidad", Madrid, Fundación Telefónica.

Gewerc, A. (coord.) (2007), "Universidad y sociedad del conocimiento: ¿Es el e-learning la única respuesta?" [en línea] http://unisic.usc.es/informes/Informe_final_proyectoADefinitivo.pdf.

INE (Instituto Nacional de Estadística) (2012), Bolivia. Características de la población y vivienda. Censo Nacional de Población y Vivienda 2012 [en línea] http://www.ine.gob.bo:8081/ censo2012/PDF/resultadosCPV2012.pdf.

Instituto de Evaluación y Asesoramiento Educativo/Neturity/ Fundación Germán Sánchez Ruipérez (2007), Las tecnologías de la información y de la comunicación en la educación. Informe sobre la implantación y el uso de las TIC en los centros docentes de educación primaria y secundaria (curso 2005 2006), Madrid [en línea] http://www.oei.es/tic/TICCD.pdf.

IRFA (Instituto Radiofónico Fe y Alegría) [en línea] http://www. irfabolivia.org/.

Lago, S. (2012), "Inclusión digital en la educación pública argentina. El programa Conectar Igualdad", Revista Educación y Pedagogía, vol. $24, \mathrm{~N}^{\circ} 64$ [en línea] http://aprendeenlinea.udea.edu.co/ revistas/index.php/revistaeyp/article/viewFile/14204/12547.

Ministerio de Educación (2014), "Gobierno inició la entrega de computadoras quipus a estudiantes de primero a sexto secundaria de Tarija" [en línea] http://www.minedu.gob.bo/ index.php/component/k2/3-noticias-recientes/3056-gobiernoinicio-la-entrega-de-computadoras-quipus-a-estudiantes-desecundaria-en-tarija.

(2011), "Una computadora por docente" [en línea] http:// computadora.educabolivia.bo/.

(2010), "Ley de la Educación "Avelino Siñani-Elizario Pérez", [en línea] http://www.oei.es/quipu/bolivia/Leydla\%20.pdf. (2006), "Programa Nacional Tics. Tecnologías de información y comunicación para el fortalecimiento del sistema educativo y el desarrollo comunitario" [en línea] http://www. gesci.org/old/files/docman/About_Programa_Nacional_de_ TICS.pdf.

Ministerio de Hidrocarburos y Energía (2010), "Plan de Universalización Bolivia con Energía 2010-2015” " [en línea] http://www2.hidrocarburos.gob.bo/phocadownload/PLAN\%20 DE\%20UNIVERSALIZACI\%C3\%93N\%20BOLIVIA\%20 CON\%20ENERG\%C3\%8DA.pdf.

Morduchowicz, R. (2012), Los adolescentes y las redes sociales, Madrid, Fondo de Cultura Económica.

Naciones Unidas (2001), Informe sobre desarrollo humano 2011. Poner el adelanto tecnológico al servicio del desarrollo humano, Madrid, Mundi-Prensa Libros S.A. [en línea] http:// hdr.undp.org/sites/default/files/hdr_2001_es.pdf.

NTIA (Administración Nacional de Telecomunicaciones e Información) (1999), "Falling Through the Net: Defining the Digital Divide" [en línea] http://www.ntia.doc.gov/legacy/ntiahome/fttn99/ contents.html.

ocDE (Organización de Cooperación y Desarrollo Económicos) (2001), Understanding the Digital Divide, París [en línea] http://www.oecd.org/sti/ieconomy/1888451.pdf.

OEI (Organización de Estados Iberoamericanos para la Educación, la Ciencia y la Cultura) (2011), La integración de las TIC en la escuela. Indicadores cuantitativos y metodología de la investigación [en línea] http://www.oei.es/idie/Integracion TIC.pdf. 
Red TICBolivia [en línea] http://www.ticbolivia.net/.

Robinson, S.S. (2005), "Reflexiones sobre la inclusión digital", Nueva Sociedad, № 195 [en línea] http://www.nuso.org/upload/ articulos/3244_1.pdf.

Rovira, S. y G. Stumpo (comp.) (2013), Entre mitos y realidades. TIC, políticas públicas y desarrollo productivo en América Latina (LC/L.3600), Santiago de Chile, Comisión Económica para América Latina y el Caribe [en línea] http://www.iadb. org/intal/intalcdi/PE/2013/10767.pdf.

Severin, E. (2010), “Tecnologías de la información y la comunicación (TICs) en educación. Marco conceptual de indicadores, Notas técnicas, $\mathrm{N}^{\circ} 6$ [en línea] http://idbdocs.iadb.org/wsdocs/ getdocument.aspx?docnum $=35128349$.

TACCLE (2009), Recursos didácticos para la creación de contenidos para entornos de aprendizaje [en línea] http://www. taccle.eu/index 2 .php?option $=$ com_docman\&task $=$ doc view $\&$ gid $=16 \&$ Itemid $=46$.
Terrazas, L. y J. Ibarra (2013), Estrategia de integración de las TIC en el sistema de educación en los municipios de La Paz. y El Alto [en línea] http://www.pieb.com.bo/sipieb_notas. php?idn=8169.

UNESCO (Organización de las Naciones Unidas para la Educación, la Ciencia y la Cultura) (2013a), "Uso de las TIC en la educacion en América Latina y el Caribe. Análisis regional de la integración de las TIC en la educación y de la aptitud digital (e-readiness)", Quebec [en línea] http://www.uis. unesco.org/Communication/Documents/ict-regional-surveylac-2012-sp.pdf.

(2013b), Directrices de la UNESCO para las políticas de aprendizaje móvil, París [en línea] http://unesdoc.unesco.org/ images/0021/002196/219662s.pdf.

Velásquez, V. (2013), "Las computadoras donadas a los maestros no son empleadas en el aula", El Nacional, 2 de julio [en línea] http://www.elnacionaltarija.com/?p=33769. 